\title{
$\mathrm{LPG} /$ 가솔린 $\mathrm{Bi}-\mathrm{Fuel}$ 엔진성능에 관한 실험적 고찰
}

\author{
전봉준 ${ }^{1}$, 박명호 ${ }^{2 *}$ \\ ${ }^{1}$ 한국폴리텍IV 대학 제천캠퍼스 \\ ${ }^{2}$ 강원대학교 기계자동차공학부
}

\section{An Experimental Study on Engine Performance of LPG/Gasoline Bi-Fuel}

\author{
Jun, Bong Jun ${ }^{1}$ and Park, Myung $\mathbf{H o}^{2^{*}}$ \\ ${ }^{1}$ Korea Politechnic IVColleges, Dean \\ ${ }^{2}$ Dept. of Mechanical \& Vehicle Engneering, Kangwon National University, Professor
}

\begin{abstract}
요 약 본 논문의 목적은 점화시기의 변화가 $\mathrm{LPG} /$ 가솔린 겸용차량에 미치는 영향을 살펴보기 위한 것으로 가솔린 전용연료 모드를 LPG 전용연료 모드로 진각시킨 제어시스템을 제안하여 엔진회전수(1500rpm, 2000rpm) 및 점화시기 $\left(5^{\circ}, 10^{\circ}, 15^{\circ}, 20^{\circ}\right)$ 의 변화에 따른 실린더내의 가스압력, 압력상승률 및 열발생률을 측정하였다. 그 결과 실런더내의 가스 압력 및 압력상승률은 기관의 회전속도가 1500rpm 및 2000rpm 모두 점화시기가 진각될수록 증가하였으나, $20^{\circ}$ 부근에 서의 압력상승률값만 약간 낮게 나타났다. 또한, 열발생률은 $1500 \mathrm{rpm}$ 에서 점화시기가 진각될수록 증가하였으며 $2000 \mathrm{rpm}$ 의 $20^{\circ}$ 부근에서 감소하는 경향을 볼 수 있었다.
\end{abstract}

\begin{abstract}
The purpose of this study is to investigate how the ignition spark timing conversion influences the engine performance of LPG/Gasoline Bi-Fuel engine. We propose the control system which can advance the ignition spark timing in LPG fuel mode more than used in gasoline fuel mode. In order to investigate the engine performance during combustion, engine performance are sampled by data acquisition system, for example cylinder pressure, pressure rise rate and heat release rate, while change of the $\operatorname{rpm}(1500,2000)$ and the ignition timing advance $\left(5^{\circ}, 10^{\circ}, 15^{\circ}, 20^{\circ}\right)$

As the result, between 1500rpm and 2000rpm, the cylinder pressure and pressure rise rate was increased when the spark ignition was advanced but pressure rise rate at $20^{\circ}$ was smaller value. Also, the heat release rate at $1500 \mathrm{rpm}$ was increased but it was lower around $20^{\circ}$ at $2000 \mathrm{rpm}$.
\end{abstract}

Key Words : LPG(Liquefied Petroleum Gas), Bi-Fuel Engine, Ignition Timing Advance, Cylinder Pressure, Pressure Rise Rate, Heat Release Rate

\section{1. 서론}

엔진의 설계 또는 개발에 있어서 중요하게 고려해야 할 사항은 차량의 성능에 크게 영향을 미치는 엔진출력 과 연비향상을 위한 엔진의 효율, 환경오염을 줄이기 위 한 유해배출물의 저감이라고 볼 수 있다. 미국의 경우 엔 진의 출력증가를 기본적인 과제로 채택하여 1960년 캘리 포니아주의 자동차 배기가스규제 및 1967년 연방규제 등
의 법규제정을 시작으로 1970년대까지 환경문제 및 공해 저감이 중요한 사회의 요구사항이었다.

그 이후 오일파동으로 인한 유가상승은 엔진설계시 연 비향상에 더욱 큰 비중을 두게 하였으며 현재는 모든 분 야에서 환경오염을 줄이는 추세에 따라 희박연소엔진 및 대체연료를 사용한 엔진개발 등 유해배출물 억제를 위한 연구가 활발히 진행되고 있다. 특히, $\mathrm{LPG}$ (Liquefied Petroleum Gas)는 여러 대체연료 중 쉽게 구할 수 있는

*교신저자 : 박명호(parkmh@kangwon.ac.kr)

접수일 09년 01월 06일 수정일 (1차 09년 05월 07일, 1차 09년 06월 10일, 3차 09년 07월 16일) 게재확정일 09년 07월 22일 
기체연료로 가솔린과 비교하여 옥탄가가 높고 고압축비 를 이용할 수 있으며 연료첨가물 없이도 엔진의 노킹을 방지할 수 있는 등 연료로서의 많은 장점을 가지고 있다. 또한, $\mathrm{LPG}$ 엔진의 경우 기존엔진에 특별한 구조변경 없이 도 사용할 수 있고 엔진개조시 경제적인 장점 때문에 최 근들어 $\mathrm{LPG}$ 사용차량은 점차 증가추세에 있다고 볼 수 있다[1].

특히, 가솔린기관을 LPG로 전환했을 경우의 연소특성 에 관한 과거연구를 살펴보면, Lowi $\mathrm{Jr}$ 등은 일산환탄소, 탄화수소, 질소산화물 및 이산화탄소 등의 주요 유해배출 물의 경우 가솔린기관과 비교하여 $20 \sim 60 \%$ 정도 감소하 며, 이는 탄화수소가 3 배 가량 증가하는 $\mathrm{CNG}$ (Compression Natural Gas)보다 좋은 대체연료라고 보고하고 있다[2]. 그러나, Gerini 등은 LPG연료가 대체 연료로서의 많은 장점을 갖고 있는 반면, 혼합기의 단위 질량당 발열량은 높지만 단위체적당 발열량이 가솔린과 비교하여 $5 \%$ 정도 작고 가스상태로 공급되기 때문에 고 부하 영역에서 5 $10 \%$ 정도의 출력저하 및 충전효율의 감소를 문제점으로 지적하였다[3]. 또한, Sierens 등은 액 체분사에 관한 연구에서 실험과 이론적 연구를 통하여 MPI 액체분사시스템을 개발하였는데, 증발식 LPG 엔진 에서는 $15 \%$ 정도의 출력저하를 나타내는 반면 액상분사 시스템에서는 가솔린과 거의 유사한 출력을 유지하며 연 료소비량 및 유해배출물의 감소또한 동시에 달성하였음 을 발표하였다[4].

이상의 연구를 종합하여 볼 때 LPG 연료는 경제적이 고 청정한 연료임이 틀림없으나 $\mathrm{LPG}$ 연료를 가스상태로
공급받는 현재의 LPG 엔진은 점화시기가 느린 가솔린의 것을 그대로 사용하고 있으므로 연소지연으로 인한 엔진 출력 및 차량 연비향상은 물론 배기가스 개선에 악영향 을 미칠것으로 사료된다.

따라서, 이러한 문제점을 개선하기 위한 한 방법으로 가솔린기관 전용 전자제어 $\mathrm{ECM(Engine} \mathrm{Control} \mathrm{Module)}$ 을 $\mathrm{LPG}$ 연료전용 전자에서 $\mathrm{ECM}$ 으로 점화시기를 진각시 켜 MBT(Minimum advance for the Best Torque)제어를 통한 출력향상을 도모하는 한 방법을 한 예로 들 수 있다 [5].

즉, LPG 연료의 경우 연소속도(Burning Velocity)가 가솔린과 비교하여 빠르며 착화온도가 높기 때문에 상대 적으로 점화시기가 진각되어야 하며, 높은 옥탄가로 인해 점화진각에 의한 노킹의 영향또한 적다고 사료된다.

따라서, 본 연구에서는 $\mathrm{LPG}($ 부탄 $70 \%$,프로판 $30 \%$ )를 연료로 사용하였을 때 기관의 엔진출력 및 차량연비 향 상을 목적으로 Gasoline 및 LPG Bi-Fuel 차량의 엔진점 화시기를 변환하여 엔진회전수 및 스로틀 개도의 변화에 따른 실린더내의 가스압력, 압력상승률 및 열발생률 등에 미치는 영향에 관한 비교·검토를 수행하였다.

\section{2. 실험장치 및 실험방법}

\section{1 실험장치}

그림 1 은 본 연구에 사용된 실험장치의 개략도를 나타 내고 있으며 실험장치는 MFI DOHC 전자제어엔진, 와류

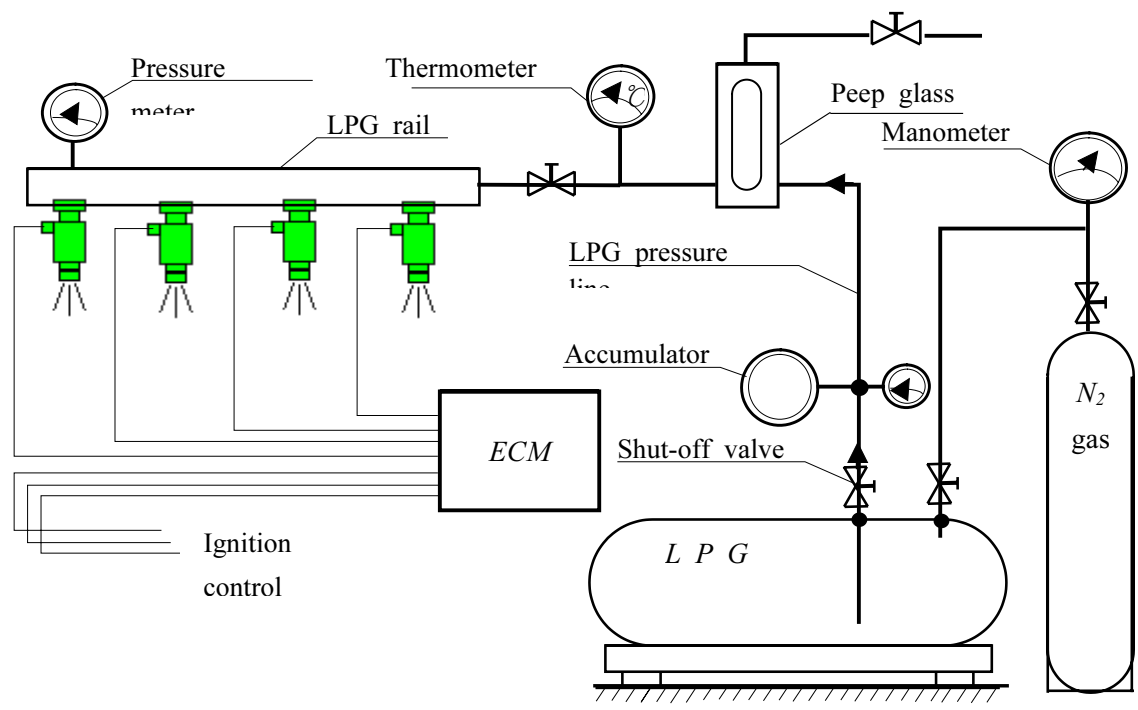

[그림 1] LPG 연료분사 제어시스템 개략도 
식 동력계, 스로틀밸브 구동장치, 데이터처리장치 및 기 타 측정장치로 구성하였다.

특히, 본 연구에 사용된 엔진은 배기량 $2000 \mathrm{cc}$ 와 압축 비 9 : 1을 갖는 4기통 가솔린엔진을 사용하였고, 엔진으 로부터 발생되는 출력 및 부하를 제어하고 계측하기 위 한 동력계는 크랭크축에 직렬로 연결된 와전류방식(eddy current)으로 흡수식을 채택하였으며 제원은 표 1에 나타 내었다. 실험장치중 LPG 연료공급은 LPG의 액상유지를 위하여 액화에 필요한 압력(20 bar) 이상으로 가압하여 공급하였으며 인젝터의 분사압력은 고압질소 가스로 조 정하였다. 또한, 엔진의 점화시기 및 연료량 등은 엔진제 어장치(ECM)로 제어되며 $\mathrm{PC}$ 를 통하여 실시간 제어와 데 이터 취득이 가능하도록 설치하였다. 스로틀 밸브는 개도 를 정확히 제어하기 위해 스테핑 모터를 $\mathrm{D} / \mathrm{A}$ 컨버터에 연결하여 컴퓨터에서 조작할 수 있도록 하였고, 정방향과 역방향으로 펄스당 $0.9^{\circ}$ 까지 회전 및 속도조절이 가능하 며 저속에서의 슬립을 방지하기 위해 모터축에 $10: 1$ 의 감속기를 부착 풀리에 연결하였다. 표 2에 스테핑 모터와 모터 구동 $\mathrm{D} / \mathrm{A}$ 컨버터 장치의 제원을 나타내었다. 정적 상태에서의 실린더내의 압력과 열발생률의 측정은 $100 \mathrm{kHz}$ 용량의 16 채널 $\mathrm{A} / \mathrm{D}$ 컨버터가 사용되었으며 제원 은 표 3 과 같다.

[표 1] 엔진제원

\begin{tabular}{|c|c|c|c|}
\hline Item & \multicolumn{3}{|c|}{ Specifications } \\
\hline Type & \multicolumn{3}{|c|}{ In-line 4-cylinder $\mathrm{DOHC}$} \\
\hline $\begin{array}{l}\text { Displacement volume } \\
{[\mathrm{cc}]}\end{array}$ & \multicolumn{3}{|l|}{1997} \\
\hline Bore $[\mathrm{mm}] \times$ Stroke $[\mathrm{mm}]$ & \multicolumn{3}{|c|}{$85 \times 88$} \\
\hline Compression ratio & \multicolumn{3}{|l|}{$9.0: 1$} \\
\hline Firing order & \multicolumn{3}{|c|}{$1-3-4-2$} \\
\hline Fuel injection type & \multicolumn{3}{|c|}{ Intake port injection } \\
\hline Fuel injector & \multicolumn{3}{|c|}{$\begin{array}{l}12 \mathrm{~V}, 14.7 \Omega, \text { 4-hole } \\
\text { Current control } \\
\text { : Saturation Type }\end{array}$} \\
\hline Ignition timing & \multicolumn{3}{|c|}{ BTDC $5^{\circ}$ at idling speed } \\
\hline Ignition system & \multicolumn{3}{|c|}{ Direct ignition system } \\
\hline \multirow{4}{*}{ Valve timing } & IVO & $26^{\circ}$ & BTDC \\
\hline & IVC & $46^{\circ}$ & ABDC \\
\hline & EVO & $55^{\circ}$ & BBDC \\
\hline & EVC & $9^{\circ}$ & ATDC \\
\hline
\end{tabular}

[표 2] 스테핑 모터와 모터구동 D/A 컨버터 제원

\begin{tabular}{|c|c|c|}
\hline \multicolumn{2}{|r|}{ Item } & Specifications \\
\hline $\begin{array}{l}\text { Stepping } \\
\text { Motor }\end{array}$ & $\begin{array}{l}\text { Type } \\
\text { Power output } \\
\text { Maker }\end{array}$ & $\begin{array}{l}\text { DC } 4.7 \text { V(1.8 A) } \\
\text { Max. } 7.35 \mathrm{~kW} \\
\text { SANYO }\end{array}$ \\
\hline $\begin{array}{l}\mathrm{D} / \mathrm{A} \\
\text { Convertor }\end{array}$ & $\begin{array}{l}\text { Model } \\
\text { Operating mode } \\
\text { Pull-up voltage } \\
\text { Pul-up resistor } \\
\text { Digital } \\
\text { Input voltage } \\
\text { Bus connector } \\
\text { I/O address range } \\
\text { Maker }\end{array}$ & $\begin{array}{l}\text { PCL-838 } \\
\text { Two pulse mode } \\
(\mathrm{CW} / \mathrm{CCW}) \\
+5 \mathrm{~V},+12 \mathrm{~V}, \\
\text { external } \\
4.7 \mathrm{k} \Omega \\
\text { Min. } 2.0 \mathrm{~V} \\
\text { Max. } 5.0 \mathrm{~V} \\
\text { Advantech Co., LTD }\end{array}$ \\
\hline
\end{tabular}

[표 3] A/D 컨버터 제원

\begin{tabular}{|l|l|}
\hline \multicolumn{1}{|c|}{ Item } & \multicolumn{1}{|c|}{ Specifications } \\
\hline Model & CHE-74 \\
Input Channel & 16 Channel \\
Transducer Connected & Strain Gage Type Sensor \\
Gage Resister & 120,350 \\
Calibration Signal & $1 \mathrm{mV} / \mathrm{V}$ \\
Bridge Supply Voltage & $0.5 \mathrm{~V}$ DC to 5V DC adjust \\
Output Signal & $5 \mathrm{~V}$ DC \\
Accuracy Class & $0.1 \%$ F.S \\
Supply Voltage & AC 110 or AC 220V \\
Sampling Rate & Dynamic(0.001s/Channel $)$ \\
Data Bit & 12 bits \\
Acquition Module & $100 \mathrm{kHz}$ \\
Desk Top & $486 / 50 \mathrm{Mhz}$ HDD 320 MB \\
Printer & GP Laser \\
Maker & Chen He Co., LTD. \\
\hline
\end{tabular}

\section{2 실험방법}

본 실험은 액상분사식 LPG 엔진의 점화시기의 변화가 기관성능에 미치는 영향을 규명하기 위하여 $\mathrm{KS}$ (한국산 업규격)의 기관성능시험 규정에 따라서 엔진회전수 $1500 \mathrm{rpm}$ 및 $2000 \mathrm{rpm}$ 에서 스로틀 밸브의 개도를 $30 \%$, 점 화시기는 $\mathrm{TCM}$ 을 설치하여 수동모두에서 $5^{\circ}, 10^{\circ}, 15^{\circ}, 20^{\circ}$ 진각시켰으며 기관의 운전은 인젝터 분사압력 $3 \mathrm{bar}$, 냉각 
수온도 $80 \pm 2{ }^{\circ} \mathrm{C}$, 흡기온도 $15 \pm 1{ }^{\circ} \mathrm{C}$ 의 상태에서 실험을 수 행하였고 또한 기관의 성능특성에 미치는 영향을 규명하 기 위하여 정상운전, 부하상태에서의 실린더내의 가스압 력, 압력상승률 및 열발생률에 대한 값을 측정하였다.

\section{3. 실험결과}

\section{1 실린더내의 가스압력}

그림 2는 엔진회전수 $1500 \mathrm{rpm}$, 스로틀 개도 $30 \%$, 점 화시기를 $5^{\circ}, 10^{\circ}, 15^{\circ}, 20^{\circ}$ 까지 진각시키면서 실린더내의 압력발생을 측정하여 점화진각이 기관의 연소압력에 미 치는 영향을 나타낸 것으로 그림에서 볼 수 있듯이 점화 시기가 진각될수록 실린더내의 가스압력은 선형적으로 증가하였고, 진각양이 증가할수록 최고값이 상사점에 근 접하는 경향을 나타내었다. 즉, 이것은 실린더내의 압력 은 흡기량, 공연비가 일정할 때 점화시기를 진각시킬수록 최고압력이 높아지고 또한 최고압력의 위치도 상사점 (TDC)에 가까워진다는 이론과 잘 일치하고 있으며, 점화 진각량이 $5^{\circ}$ 일때보다 $20^{\circ}$ 일때 약 $2.65 \mathrm{bar}$ 정도 높게 나타 났다. 그림 3은 엔진회전수가 2000rpm, 스로틀개도 $30 \%$ 에서 그림 2와 동일한 방법으로 진각시키면서 실린더내 의 압력발생에 대한 데이터를 얻어 점화진각이 기관의 연소압력에 미치는 영향을 나타낸 것이다.

결과를 살펴보면 점화시기가 $5^{\circ}$ 에서 $15^{\circ}$ 까지 진각될 수록 가스압력또한 선형적으로 증가하였으나, 진각량이 $20^{\circ}$ 의 경우 큰 변화가 없었는데, 그 원인으로 진각량이 큰 경우 폭발압력에 의한 마찰손실 발생이 원인으로 사 료된다.

\section{2 실린더내의 압력상승률}

그림 4와 그림 5는 엔진회전수를 각각 $1500 \mathrm{rpm}$ 및 $2000 \mathrm{rpm}$ 으로 설정하고, 스로틀 개도 $30 \%$, 점화시기를 $5^{\circ}, 10^{\circ}, 15^{\circ}, 20^{\circ}$ 까지 진각시켰을 때 실린더내의 압력상승 률에 미치는 영향을 나타낸 것이다. 두 결과 모두 점화시 기가 진각될수록 실린더 내의 압력상승률도 선형적으로 증가하면서 $\mathrm{TDC}$ 에 접근하였으나, 점화진각이 $20^{\circ}$ 부근 에서 약간 낮아지는 것은 실린더내의 가스압력과 같이 점화진각이 클수록 $\mathrm{TDC}$ 전에서 최고압력이 형성되어 마 찰손실이 증가한 결과라 사료된다.

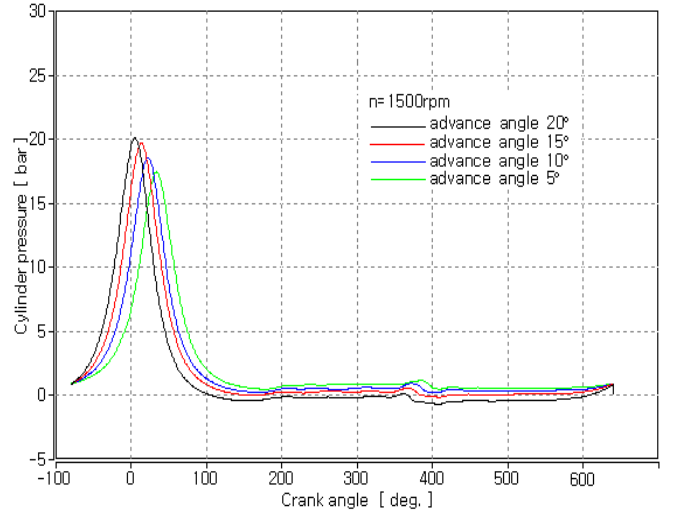

[그림 2] 실린더내의 압력발생곡선 (스로틀개도 $30 \%, 1500 \mathrm{rpm}$ )

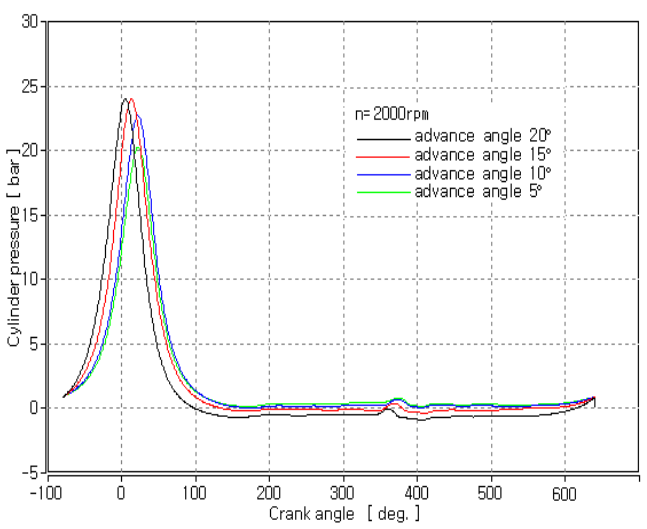

[그림 3] 실린더내의 압력발생곡선 (스로틀개도 $30 \%, 2000 \mathrm{rpm}$ )

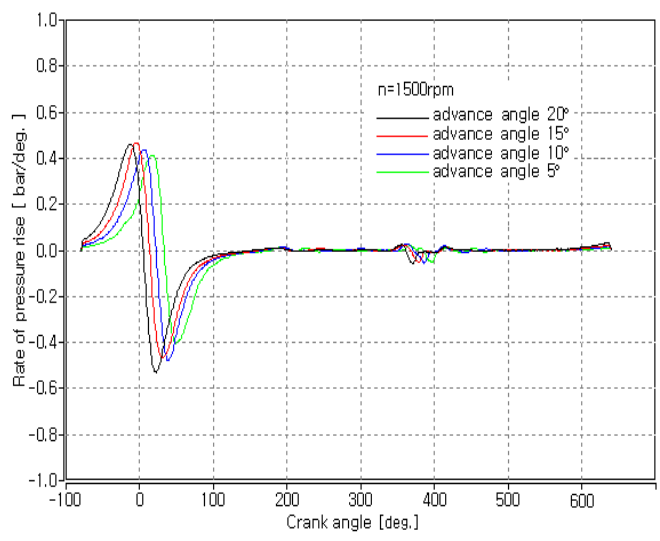

[그림 4] 실린더내의 압력상승률 (스로틀개도 $30 \%, 1500 \mathrm{rpm}$ ) 


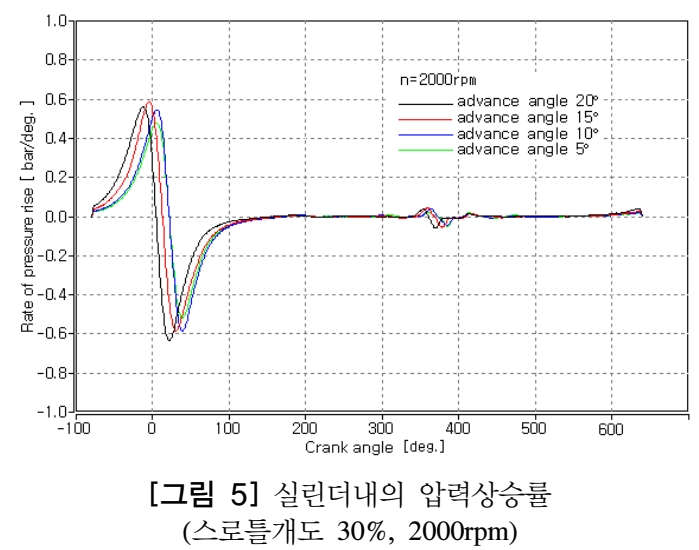

\section{3 실린더내의 열발생률}

그림 6과 그림 7은 엔진회전수 $1500 \mathrm{rpm}$ 및 2000rpm 에서 스로틀 개도 $30 \%$, 점화시기를 $5^{\circ}, 10^{\circ}, 15^{\circ}, 20^{\circ}$ 까지 진각시켰을 때 실린더내의 열발생률에 미치는 영향을 나 타낸 것으로 그림 7의 경우 점화시기가 진각될수록 열발 생률은 증가하였으며 $2000 \mathrm{rpm}$ 의 경우 점화시기가 진각 될수록 열발생률의 증가폭은 $20^{\circ}$ 일때 보다 작게 나타났다.



[그림 6] 실린더내의 열발생률 (스로틀개도 $30 \%, 1500 \mathrm{rpm}$ )

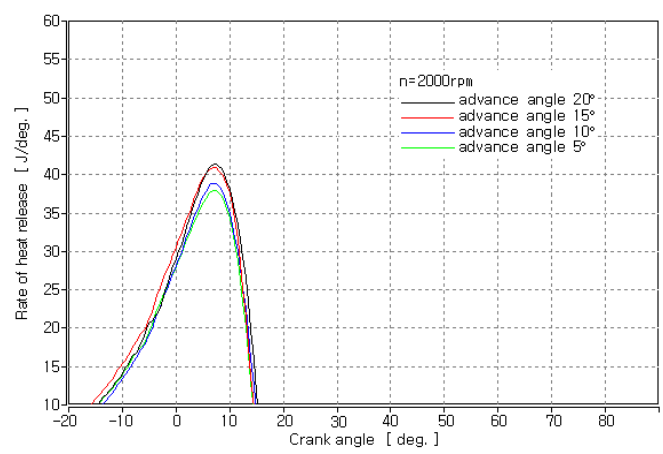

[그림 7] 실린더내의 열발생률 (스로틀개도 $30 \%, 2000 \mathrm{rpm}$ )

\section{4. 결 론}

가솔린 엔진에 LPG 액상분사장치를 적용하기 위한 연 구로서 Gasoline 및 LPG Bi-Fuel 차량의 엔진점화시기를 변환하여 엔진 회전수 및 스로틀 개도의 변화에 따른 실 린더내의 가스압력, 압력상승률 및 열발생률을 비교·분석 한 결과 다음과 같은 결론을 얻어낼 수 있었다.

1. 실린더내의 가스압력은 엔진회전수가 $1500 \mathrm{rpm}$ 일때 점화진각량이 $5^{\circ}$ 일때 보다 $20^{\circ}$ 일때가 최대압력이 약 2.65bar정도 높게 나타났으며 2000rpm의 경우 점화시기가 $5^{\circ}$ 에서 $15^{\circ}$ 까지는 진각될수록 실린더 내 가스압력이 선형적으로 증가됨을 확인할 수 있 었다.

2. 압력발생률은 $1500 \mathrm{rpm}$ 및 2000rpm 모두 점화시기 가 진각될수록 실린더내의 압력상승률도 선형적으 로 증가하였으며, 점화진각이 $20^{\circ}$ 부근에서 약간 낮 아지는 경향을 볼 수 있었다.

3. 실린더내의 열발생률은 $1500 \mathrm{rpm}$ 에서 점화시기가 진각될수록 증가하였으며 $2000 \mathrm{rpm}$ 의 경우 $20^{\circ}$ 부근 에서 약간 감소하는 경향을 볼 수 있었다.

\section{참고문헌}

[1] 지덕림, "LPG 자동차 연료장치의 구조기준(I/II)", 가 스안전. pp.39, 1999.

[2] A. Lowj Jr. and W.P.L. Carter, "A method for evaluating the atmospheric ozone impact of actual vehicle emissions", SAE paper 900710, 1990.

[3] A. Gerini, G. Monnier and R. Bonetto, "Lltra low emission vehicle using LPG engine fuel", SAE paper 961079, 1996.

[4] R. Sierens, "An experimental and theoretical study of liquid LPG injection”, SAE paper 922363, 1992.

[5] 전봉준 외, "LPG 및 가솔린 겸용 차량의 엔진 점화 시기 변환 제어시스템 개발”, 한국박용기관학회지, 제 27권, 제1호, pp.117-123. 2003. 
전 봉 준(Bong-Jun Jung)

[정회원]

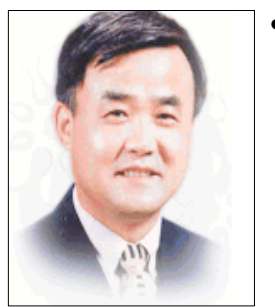

- 2009년 7월 현재 : 한국폴리텍 IV대학 제천캠퍼스 학장

<관심분야>

열유체, 내연기관분야, 에너지분야

박 명 호(Myung-Ho Park)

[정회원]

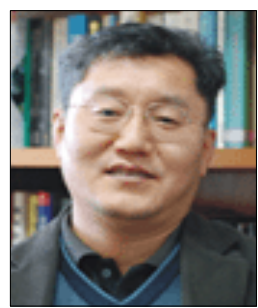

- 1987년 2월 : 강원대학교 기계 공학과(공학사)

- 1992년 2월 : 강원대학교 대학 원 기계공학과(공학석사)

- 1996년 3월 : 九州工大 대학원 기계공학과(공학박사)

- 2002년 3월 현재 : 강원대학교 기계자동차공학부 교수

<관심분야>

열유체, 연소분야, 에너지분야 